\title{
Ação de responsabilidade social para competências em informação
}

Lucas Almeida Serafim

Professor Assistente do Curso de Biblioteconomia da Universidade Federal do Ceará, Campus Cariri Mestre em Ciência da Informação (UFPB) Doutorando em Ciência da Informação (UFPB)

Gustavo Henrique de Araújo Freire

Doutor em Ciência da Informação (UFRJ) Chefe do Departamento de Ciência da Informação Editor da Revista Informação \& Sociedade: Estudos Coordenador Operacional do Doutorado Interinstitucional em Ciência da Informação UFPB/UFMG/UFPE/UFPB/CCSA/DCI

Expressa o desenvolvimento de competências em informação como ação de responsabilidade social da Ciência da Informação. Para tanto, destaca o valor crescente da informação nos diferentes contextos e, consequentemente, a relevância social das competências em informação para todos. Conclui que a promoção das competências em informação constitui ação socialmente justa dos que compõem o campo dos profissionais da informação na medida em que o uso eficiente e crítico das informações torna-se um fator essencial de inclusão social.

Palavras-chave: Competências em Informação; Responsabilidade social da Ciência da Informação; Sociedade da Informação. 


\section{Social responsibility action for information literacy}

The information literacy development is presented as a social responsibility action of Information Science. In doing so, this article highlights the information value in different social contexts, and consequently the social relevance of information literacy skills for everyone. It concludes that the promotion of information literacy constitutes a socially responsible action of those who compose the information professional field, based on the fact that the efficient and critical use of information becomes an essential factor of social inclusion.

Keyword: Information literacy; Social Responsibility of Information Science; Information society.

\section{Introdução}

Este artigo resulta de pesquisa desenvolvida em curso de mestrado, que teve como objetivo geral analisar as ações de desenvolvimento de competências em informação para os docentes do curso de Agronomia da Universidade Federal do Ceará - Campus do Cariri, tendo como suporte o mapeamento do regime de informação local (SERAFIM, 2011). Ao considerar as habilidades informacionais um fator-chave para a inclusão social das pessoas contemporâneas, tornou-se relevante, nesta pesquisa, a análise do desenvolvimento de competências em informação como ação de responsabilidade social dos que fazem parte do campo da Ciência da Informação.

As habilidades para localizar, avaliar e usar efetivamente informações tornaram-se necessárias e complexas, na medida em que cresceu o volume informacional disponível para o desenvolvimento das atividades humanas. No âmbito dos serviços bibliotecários, a capacitação de usuários de informação, até meados da década de 1980, era uma preocupação restrita ao bom uso das bibliotecas. A educação de usuários consistia em 
[...] vários programas de instrução, educação e exploração oferecidos pelas bibliotecas aos seus usuários para capacitálos a fazer um uso mais eficaz, eficiente e independente das fontes, recursos e serviços de informação que estas bibliotecas oferecem (FLEMING, 1990, p. 9 apud CAREGNATO, 2000, p. 49).

No emergir de uma sociedade centrada no conhecimento e em informação, o treinamento de usuários das bibliotecas fomentou o surgimento de um movimento para desenvolver competências em informação, cujo marco histórico é o conceito de information literacy, expressão cunhada pelo estadunidense Paul Zurkowski (1974).

As competências em informação, de um modo geral, são compreendidas na literatura especializada como um conjunto de habilidades para localizar, manipular, avaliar e usar a informação, eficiente e eticamente, em variados campos. A pessoa competente em informação (information literate) é aquela apta a desempenhar suas atividades na nova sociedade (PINTO; CÓRDÓN; DIAZ, 2010). Neste estudo, emprega-se a dicção "competências em informação" (no plural) como tradução de information literacy (no singular), entendendo-se que não seria apenas uma, mas um conjunto de habilidades informacionais inerentes à extensão proposta por Zurkowski (1974).

É importante ressaltar que as tentativas de traduzir a unidade de ideia infomation literacy pelos países que não falam a Língua Inglesa deu origem a uma variada terminologia, observada em diversos estudos: "Competência Informacional", "Competência em Informação", "Alfabetização Digital", "letramento informacional", "literacia informacional", dentre outros.

Neste artigo, a ideia de "competências em informação" segue, de certo modo, alguns estudos de Língua Portuguesa que preferem a palavra "competências" em vez de "alfabetização", na tradução do vocábulo literacy (VIRKUS, 2003). Compreende-se que a palavra "competências" é mais apropriada para o entendimento de habilidades informacionais específicas, que transpõem os métodos de alfabetização tradicionais. Já a escolha por "competências em informação", e não "competências informacionais", outra unidade bastante recorrente, fundamenta-se no fato de, que embora sejam palavras com significados similares, o qualificador do substantivo literacy é um outro substantivo, information, e não um adjetivo (informational). 
$\mathrm{Na}$ Era da informação digital, este conjunto de aptidões inclui habilidades no uso das tecnologias da informação e comunicação (TIC), bem como no encorajamento à criatividade e ao pensamento crítico. Do ponto de vista do atual panorama tecnológico, a dicção competências em informação assume outra vestimenta. Isto ocorre pelo fato de que a informação "[...] necessita de um contexto para ser compreendida" (FREIRE, G.; FREIRE, I., 2009, p. 101).

Nesta mesma perspectiva, Koltay (2011) exprime outros exemplos:

a) competências em mídias (media literacy) - habilidade para decodificar, avaliar, analisar e produzir tanto mídias eletrônicas quanto impressas; preza um relacionamento autônomo crítico com todas as mídias;

b) competências visuais (visual literacy) - aptidão para discriminar e interpretar ações visíveis, objetos e símbolos, naturais ou produzidos pelo homem;

c) competências digitais (digital literacy) - capacidade para entender e usar a informação de uma variedade de fontes digitais, incluindo pesquisar na internet, navegar por hipertextos e coletar informações relevantes e confiáveis;

d) competências nas tecnologias emergentes (emerging technology literacy) - agilidade para se adaptar continuamente para entender, avaliar e utilizar as emergentes inovações em tecnologia da informação, de modo que a pessoa não fique prisioneira de antigas tecnologias, tornando-a apta a tomar decisões inteligentes ao adotar as mais novas; e

e) competências multiculturais (multicultural literacy): mestria para reconhecer, comparar, contrastar e apreciar similaridades e diferenças nos comportamentos culturais, crenças e valores dentro e entre culturas.

Koltay (2011, p. 219) trata as competências em informação de modo isolado das que ele descreve no parágrafo anterior, limitando-as à comunicação verbal, ponto de vista não corroborado por este ensaio justamente pela característica múltipla da informação em diferentes realidades. Entende-se que a informação "[...] constitui-se a partir das formas culturais de semantização de nossa experiência do mundo e seus 
desdobramentos em atos de enunciação, de interpretação, de transmissão e de inscrição" (GONZALEZ DE GOMEZ, 2003, p. 32).

A informação, portanto, é contextual ou "relacional", e que, por isso, sua definição ou valoração depende do contexto (GONZALEZ DE GOMEZ, 2003, p. 34). Corroborando, Virkus (2003), Pinto, Cordón e Diaz, (2010) e Owusu-Ansah (2005) acreditam que o debate por um conceito singular para competências em informação não tem sentido, pois os elementos culturais e estruturais dos macro e microambientes variam de um país para outro ou de uma instituição para outra.

\section{Um conceito para competências em informação}

Owusu-Ansah (2005, p. 366, tradução nossa) faz críticas contundentes às discussões sobre o conceito de competências em informação, considerando-as uma distração dos esforços de muitos bibliotecários: "parece que a cada vez que o contexto se mostra diferente, surge a necessidade por uma nova definição". Para o autor, as diferentes interpretações propostas são, em geral, "[...] as mesmas coisas em modos diferentes" (OWUSU-ANSAH, 2005, p. 366, tradução nossa). O autor chama atenção para a magnitude inquestionável das competências em informação, bastando apenas se analisar a relação entre informação, crescimento exponencial da informação e sociedade, tornando sua interpretação "[...] com diversidade aparente de objetivo e falta de consenso suficiente sobre a forma concreta de execução, que muitas vezes obscurece o significado de um conceito suficientemente claro para ser entendido com um mínimo equívoco" (OWUSU-ANSAH, 2005, p. 367, tradução nossa).

Substituir information literacy por information competency ou fluência em informação apenas muda o nome ou descritor atribuído ao conceito, sem transformar, ou melhor, esclarecer o fenômeno que o identifica. O debate continuado sobre definições apropriadas [...] não tem benefícios práticos. Tal atividade pode se tornar, todavia, uma perda de tempo e energia preciosos. Este tempo e energia poderiam ser mais significativamente gastos na busca para melhorar as capacidades dos estudantes, explorar o papel que a biblioteca pode ter neste processo, bem como em determinar a legitimidade e vontade da participação da biblioteca na educação dos estudantes competentes em informação (OWUSU-ANSAH, 2005, p. 373, tradução nossa). 
Ainda segundo o autor, tal amplitude conceitual impede até mesmo de a biblioteca reivindicar a sua propriedade total. Assim, compreendemse as competências em informação como fenômenos culturalmente construídos que capacitam aprendizes para toda a vida, estreitamente relacionadas ao modo como as comunidades exprimem suas interpretações sobre a realidade e dos resultados destas interpretações (PINTO; CÓRDÓN; DIAZ, 2010). Na inteligência de Zurkowski (1974), essas competências são necessárias frente a uma complexa e variada "infoestrutura". Para ele, as competências em informação constituem uma extensão ou evolução das iniciativas de educação de usuários de bibliotecas, pois ultrapassam a busca e recuperação de informação dos serviços bibliotecários tradicionais. Para Gonzalez de Gomez (2006), o uso do neologismo não dicionarizado "infoestrutura", uma junção dos vocábulos "informação" e "estrutura", por Zurkowski, torna-o também pioneiro da "economia do conhecimento". A "infoestrutura" engloba:

[...] a miríade de elementos necessários para sustentar a sofisticada capacidade de manipular informação que caracterizaria a economia dos Estados Unidos. Considerando que essa 'infoestrutura' seria a chave do aumento de produtividade e de aproveitamento dos talentos humanos, ao mesmo tempo em que esboça um mapeamento de seu alcance e extensão, indaga pelas possibilidades de nela se integrarem as tecnologias, os mercados e os diferentes segmentos das indústrias da informação (GONZALEZ DE GOMEZ, 2006, p. 41).

Zurkowski (1974) afirma que infraestrutura que apoia o cenário dos serviços de informação transcende as bibliotecas tradicionais, os editores e as escolas. E mais: em momentos de constantes mudanças, a abundância das informações disponíveis ultrapassa a capacidade das pessoas de avaliá-las e, consequentemente, assimilá-las. O autor observa que:

a) os procedimentos de busca por informação são diferentes, em tempos diferenciados, com propósitos diferentes;

b) há uma multiplicidade dos caminhos de acesso às fontes de informação, em resposta às mais variadas necessidades de informação das pessoas; e 
c) cada vez mais os eventos e artefatos produzidos pelos seres humanos estão relacionados à informação, exigindo um "retreinamento" de toda a população.

Badke (2010) destaca que o simples fato de Zurkowski (1974) estudar a informação como um assunto separado origina o movimento pelas competências em informação de hoje. Na concepção de Zurkowski (1974),

a) informação não é conhecimento, e, sim, conceitos ou ideias que adentram o campo de percepção de uma pessoa, e que são avaliadas e assimiladas, reforçando ou mudando os conceitos individuais de realidade e/ou habilidades para agir; deste modo, "assim como a beleza está no olho de quem vê, a informação está na mente do usuário" (ZURKOWSKI,1974, p. 4, tradução nossa); e

b) pessoas capacitadas para utilização das fontes de informação para o seu trabalho podem ser consideradas competentes em informação (information literates); elas aprenderam técnicas e habilidades para utilizar uma larga quantidade de ferramentas de informação, bem como fontes primárias para ensejar soluções de informação para os seus problemas; as outras pessoas que compõem o restante da população, como aptas para ler e escrever, não têm uma ideia do valor da informação, não possuem a capacidade de avaliá-la criticamente de acordo com as suas necessidades, sendo, portanto, deficientes em competências em informação (information illiterates).

Se as competências em informação ultrapassam a capacidade de ler e escrever, revelam-se nos países em desenvolvimento problemas básicos de alfabetização, como é o caso do Brasil, que possuem, portanto, um longo caminho a percorrer na promoção de competências em informação dos seus cidadãos (DUDZIAK, 2008).

Os atuais padrões para o desenvolvimento de competências em informação originam-se nos países nos quais os programas de competências já são uma prática. Dentre eles, destacam-se o estadunidense Information Literacy Competency Standards for Higher Education, da Association College Of Research Libraries (2000), e o The Seven Pillars of Information Literacy, da Society of College, National and University Libraries (2011), do Reino Unido. Para Virkus (2003), as 
diferenças linguísticas refletem também o nível de desenvolvimento de competências em informação, cujas publicações e iniciativas estão em sua maioria nos países industrializados de Língua Inglesa. Na Europa, por exemplo, o Reino Unido sobressai-se sobre as demais regiões daquele continente (VIRKUS, 2003).

Pinto, Córdon e Díaz (2010) consideram o "American Library Association Presidential Committee on Information Literacy: Final Report", de 1989, como um marco no moderno conceito de competências em informação. Nele, consideram-se as competências em informação um modelo mais dinâmico de aprendizado centrado no manuseio e uso de informação, de modo crítico, concebido com base em perspectiva mais ampla da função informacional na vida das pessoas.

Para Mounce (2010), este documento chama a atenção dos bibliotecários para a transição da educação de usuários de bibliotecas para as competências em informação. Já Zhang, Majid e Foo (2010, p. 720) valorizam esse relatório por contribuir para os estudos de competências em informação, já que, além de reconhecer a importância da expressão, define as aptidões de uma pessoa competente em informação: aquela capaz de reconhecer uma necessidade de informação, acessar efetivamente, avaliar e utilizar de um modo criativo as informações.

Este relatório evoluiu para o padrão mais referenciado nos estudos de competências em informação, o Information Literacy Competency Standards for Higher Education (2000), cuja origem ocorre no contexto acadêmico, na maior divisão da American Library Association (ALA), a Association of College \& Research Libraries (HOYER, 2011). Este modelo reforça a ideia de que as implicações das competências em informação não afetam apenas a vida acadêmica, mas também a sociedade como um todo (ASSOCIATION OF COLLEGE \& RESEARCH LIBRARIES, 2000).

Além de habilidades cognitivas de interpretação da informação, incluem-se aquelas relacionadas à capacidade da pessoa em lidar com os novos aparatos tecnológicos disponíveis: competências nas tecnologias da informação e comunicação (Information and Communication Technology literacy); competências digitais (Digital literacy; e-literacy); competências no uso de computadores (Computer literacy); competências tecnológicas (Technological literacy); múltiplas competências (Multiliteracies); novas competências (New literacies). (PINTO; CÓRDÓN; DIAZ, 2010). 
A atenção requerida no emprego dessas dicções é justamente em tratá-las como partes do conceito de competências em informação. Do contrário, isoladas, elas favorecem o surgimento de uma falsa ideia de que o desenvolvimento de habilidades no uso das tecnologias, por si, é suficiente para se enfrentem os desafios informacionais contemporâneos (determinismo tecnológico).

\section{Competências em informação como ação de responsabilidade social da Ciência da Informação}

O desenvolvimento das TIC, no período seguinte à II Guerra Mundial, promoveu transformações na sociedade como um todo. Embora já se soubesse a priori da existência de uma ciência cuja ocupação era estudar e compreender os fenômenos informacionais, já estudados pela Biblioteconomia em forma de registros, nasce oficialmente a Ciência da Informação (CI), durante a segunda reunião do Georgia Institute of Technology, entre os dias 12 e 13 de abril de 1962 (PINHEIRO, 2005). Nela, tinha-se o objetivo de formalizar as propriedades da informação pela aplicação da Teoria da Informação, da Teoria das Decisões e de outros construtos da Ciência cognitiva, da Lógica e/ou da Filosofia. Nesse encontro, reuniram-se cientistas e engenheiros de todo o Mundo, o que denota o caráter interdisciplinar da $\mathrm{CI}$, pela diversidade de profissionais que discutiam a questão do acúmulo informacional.

No atual estádio de evolução da $\mathrm{CI}$, permanecem as discussões básicas observadas nas décadas de 1960/70, em torno do seu status de cientificidade, o que torna a área, para Tálamo e Smit (2007, p. 23), nos moldes tradicionais da ciência, um campo teórico e científico comprometido "pela ausência de um modelo de origem consistente que Ihe confira identidade e desenvolvimento consolidado". Assim, a CI busca apoio no paradigma pós-moderno. Para Santos (1988, p. 54-56), a CI e demais campos científicos convivem em um quadro científico que passa por um momento de transição, caracterizado pela falta de confiança epistemológica que assola as ciências, não somente as sociais, como também as da natureza.

[...] Ao contrário do que se sucede no paradigma atual [moderno], o conhecimento avança à medida que seu objeto se amplia, ampliação que, como uma árvore, procede pela diferenciação e pelo alastramento das raízes em busca de novas e mais variadas interfaces [...] A ciência pós-moderna 
não segue um estilo unidimensional, facilmente identificável; o seu estilo é uma configuração de estilos construída segundo o critério e a imaginação pessoal do cientista. A tolerância discursiva é outro lado da pluralidade metodológica.

Tal instabilidade, na perspectiva de Wersig (1993), delineia mudanças no foco das pesquisas científicas, da busca por compreender como o mundo funciona para a necessidade de solucionar e lidar com problemas cada vez mais complexos e contraditórios, relacionados ao uso do conhecimento com base nas condições pós-modernas da informatização.

A trans, multi e interdisciplinaridade, ou a falta de uma unicidade conceitual e metodológica, também fundamentam a visão pós-moderna da Ciência da Informação, reflexo do seu objeto de estudo, já que

[...] a informação é um fenômeno que não se prende facilmente a conceitos e teorias gerais, estando relacionada a todas as áreas do conhecimento e se moldando aos interesses de cada uma delas. Além da dificuldade advinda da dinâmica própria ao seu objeto de estudo, construído a partir do olhar de várias disciplinas com as quais a Ciência da informação se relaciona, há uma complexa relação com o contexto histórico da sociedade ocidental, o que resulta em uma multiplicidade de abordagens (FREIRE, G.; FREIRE, I., 2009, p. 9).

Wersig (1993) acentua que na CI "ou qualquer coisa que este campo seja chamado", não haverá uma teoria, mas uma estrutura de conceitos ou modelos científicos amplos e conceitos comuns reformulados, entrelaçados com arrimo em dois aspectos: como eles foram desenvolvidos e como podem ser relacionados baseados em novos contextos que caracterizam o uso do conhecimento. Como ciência pósmoderna e subjetiva, os problemas de interesse da CI originam-se dos "[...] fenômenos sociais a partir das atitudes mentais e do sentido que os agentes conferem às suas ações" (SANTOS, 1988, p. 53). Para Freire (2006, p. 16),

Como em qualquer campo científico, também na ciência da informação será possível identificar uma rede conceitual que relaciona os vários construtos de informação entre si e as próprias noções sobre o campo científico. [...] sejam centenas as definições de informação nos vários campos da atividade científica, cada um deles irá defini-la de acordo com o seu 
interesse específico, cabendo aos pesquisadores da ciência da informação o desafio maior de determinar a própria forma.

Na mesma perspectiva, Gonzalez de Gomez (2003, p. 32-33) acentua que:

A Ciência da Informação, assim, seria aquela que estuda fenômenos, processos, construções, sistemas, redes e artefatos de informação, enquanto 'informação' for definida por ações de informação, as quais remetem aos atores que as agenciam, aos contextos e situações em que acontecem e aos regimes de informação em que se inscrevem [...] o que se denomina informação constitui-se a partir das formas culturais de semantização de nossa experiência do mundo e seus desdobramentos em atos de enunciação, de interpretação, de transmissão e de inscrição.

Gonzalez de Gomez (2003), fundamentada em Frohmann (1995), compreende a informação como "ação de informação" na qual esta pode ser considerada ou não informação, com base no contexto no qual está inserida a ação de informação. Não restrito ao aspecto cognitivo da informação, esse ponto de vista ressalta a dimensão social do objeto de estudo da CI, que possui características de materialidade, como documentos, sistemas de informação, instituições e enunciados, que são dotados de energia, força e poder (status), na medida em que são institucionalizados pela família, a escola etc. Assim, a Documentação, compreendida como as formas de materializar a informação, não teria apenas mera função de comunicação da informação, mas sim a de aferir disciplinarmente as pessoas inseridas nos regimes de informação contemporâneos (FROHMANN, 2008).

$\mathrm{Na}$ qualidade de campo estruturado e organizado de conhecimento, a CI passa a se justificar como ciência com suporte nas questões éticas e de responsabilidade social (WERSIG; NEVELLING, 1975), em uma sociedade cada vez mais complexa e globalizada. O lado social da CI, na inteligência de Cronin $(2008,466)$, não é recente e remonta as suas disciplinas ancestrais - a Documentação e a Biblioteconomia - refletindo de forma implícita ou explicita nos estudos da área uma atenção especial e atitude receptiva ao pensamento sociológico.

Du Mont (1991, p. 203) explica que o conceito de responsabilidade social é fundamentalmente ético, constituindo-se no modo como os 
profissionais da informação se preocupam com a dimensão social e os impactos dos serviços de informação. atribuída

Como campo científico, a responsabilidade social da CI pode ser

[...] a todos que a constroem e nela estão envolvidos desde a sua gestação, os arquitetos do seu desenvolvimento e avanços, enfim, aqueles que a tornaram um campo científico. [...] Trata-se de uma rede sócio-técnico-científica constituída por pesquisadores e professores, profissionais de informação de diferentes formações, instituições de ensino e pesquisa, sociedades e periódicos científicos, eventos técnico-científicos, formuladores de políticas públicas, órgãos de fomento, bibliotecas, centros, redes e sistemas de informação, tecnologias de informação e comunicação e todo o conjunto de novos recursos de informação na Internet, sejam bibliotecas virtuais, digitais, repositórios - humanos e não humanos (PINHEIRO, 2009, p. 1).

Já Freire (2004) destaca como função social dos cientistas da informação a de serem "facilitadores" da comunicação do conhecimento, pois,

[...] embora a informação sempre tenha sido uma poderosa força de transformação, o capital, a tecnologia, a multiplicação dos meios de comunicação de massa e sua influência na socialização dos indivíduos deram uma nova dimensão a esse potencial. Com isso, crescem as possibilidades de serem criados instrumentos para transferência efetiva da informação e do conhecimento, de modo a apoiar as atividades que fazem parte do próprio núcleo de transformação da sociedade.

A tradicional preocupação dos bibliotecários para a coleção, com ênfase no cuidado com os materiais dentro das bibliotecas, não abrange mais a responsabilidade social dos modernos profissionais da informação, "[...] agentes e atores sociais cuja intervenção na produção, acesso ou uso de informação, afeta a vida de terceiros, por vezes na extensão indefinida de coletivos em redes" (GONZALEZ DE GOMEZ, 2009, p. 107), preocupados ou com qualquer indivíduo ou grupo com necessidades de informação (DU MONT, 1991). Na Ciência da Informação, atenta-se para uma responsabilidade social que ultrapasse os tradicionais sistemas de recuperação da informação, exigida atualmente "no espaço deixado por 
recortes já instituídos pela biblioteconomia e demais ciências sociais" (MOSTAFA, 1996). Na visão de Du Mont (1991), a responsabilidade social dos profissionais da informação é mostrada em 4 estádios (Quadro 1) .

Quadro 1 - Responsabilidade social contínua de um profissional da informação

\begin{tabular}{c|l|l|l}
\hline \multicolumn{1}{c|}{ Estádio 1 } & \multicolumn{1}{|c|}{ Estádio 2 } & \multicolumn{1}{|c}{ Estádio 3 } & \multicolumn{1}{c}{ Estádio 4 } \\
\hline $\begin{array}{l}\text { Desenvolvimento e } \\
\text { manutenção das coleções }\end{array}$ & $\begin{array}{l}\text { Empregados } \\
\text { [internos] somente }\end{array}$ & $\begin{array}{l}\text { Usuários [internos] de } \\
\text { informação }\end{array}$ & $\begin{array}{l}\text { Sociedade como um } \\
\text { todo }\end{array}$ \\
\hline
\end{tabular}

Fonte: DU MONT (1991, p. 204, tradução nossa).

No estádio 1 , o profissional da informação promove 0 desenvolvimento e manutenção das coleções. No segundo, incluem-se nas suas responsabilidades as questões humanas em benefício dos empregados internos da organização na qual está inserido: educação e treinamentos apropriados, melhoramento das condições de trabalho, expansão dos direitos trabalhistas e melhoramento das seguranças no trabalho, por exemplo. No estádio 3, há um cuidado com a prestação de serviços com alta qualidade, uma coleção excelente e um bom relacionamento com o público. No último, os profissionais da informação assumem papel ativo na promoção da justiça social, apoiando objetivos sociais e culturais, e posições sociais. Segundo Du mont (1991), nem todos os profissionais chegam ao estádio 4 .

No âmbito da educação superior, contexto no qual foi desenvolvido este ensaio (SERAFIM, 2011), os preceitos das competências em informação confundem-se com a responsabilidade social das instituições de ensino superior. Ao garantir que os indivíduos tenham as habilidades intelectuais de argumentação e pensamento crítico, e auxiliá-los na constituição de uma estrutura que Ihes possibilite aprender a aprender, as faculdades e universidades oferecem as bases para o crescimento contínuo por meio de suas carreiras, assim como para o seu papel na qualidade de cidadãos informados e membros das comunidades (ASSOCIATION COLLEGE OF RESEARCH LIBRARIES, 2000).

Para Buarque (1991 apud MINGUILI; CHAVES; FORESTI, [2007], p. 13), a responsabilidade social da universidade no contexto brasileiro está unicamente na geração de conhecimento:

A universidade tem um único papel social: gerar saber. Para cumprir seu papel social, a universidade tem que se adiantar. 
[...] O primeiro compromisso social da universidade é com a qualidade, com o saber inédito, com o saber novo, que vai além da fronteira do saber tradicional [...] não necessitam de outro compromisso, mas não podem transigir com a mediocridade, a repetição [...] É uma pena que a universidade brasileira ainda esteja patinando na definição de seu compromisso social. Já é hora de avançar.

De modo mais abrangente, o INEP (2007, p. 90) considera que a base da responsabilidade dessas instituições está na educação como um direito social e dever do Estado "[...] especialmente no que se refere à formação acadêmico-científica, profissional, ética e política dos cidadãos, à produção de conhecimentos e promoção da ciência e da cultura". Nesta mesma perspectiva, Vallaeys (2006) compreende a responsabilidade social universitária em quatro linhas de ação institucional: na gestão interna da Universidade, na docência, na pesquisa e na projeção social.

$\mathrm{Na}$ Era Digital, os valores essenciais para a produção do conhecimento científico, como transparência, confiabilidade e independência das informações, são frequentemente ameaçados. Antes da popularização das TIC, "bibliotecários faziam parte do grupo de profissionais que assumiam a responsabilidade pela confiabilidade das informações; eles cuidadosamente formavam acervos, avaliando critérios de atualidade, precisão e credibilidade, antes de promoverem acesso aos usuários" (WALSH, 2010, p. 498, tradução nossa). Também presente na educação dos usuários de bibliotecas, esses valores refletem na transição para as competências em informação, ampliando a função dos bibliotecários, postada além do ensino dos mecanismos e técnicas avançadas de pesquisa.

Esclarecer os usuários sobre as dimensões econômicas, políticas e sócioculturais dos processos de pesquisa "[...] deveria ser responsabilidade de todos os acadêmicos preocupados com os valores relacionados à produção do conhecimento" (VAN DIJCK, 2010, p. 586, tradução nossa). Walsh (2010) ressalta a função da biblioteconomia com a proteção epistêmica dos usuários contra a desinformação que caracteriza as mídias digitais, sem ferir os princípios éticos da liberdade de acesso à informação nas tentativas de controle ou monitoramento das informações online.

As decisões no âmbito informacional são, naturalmente, caracterizadas por suas ambiguidades éticas, o que para Du Mont (1991, 
p. 213-214, tradução nossa), não significa que os bibliotecários não devam agir, pois tais ambiguidades "[...] sempre estarão presentes pois ninguém pode formular políticas que serão moralmente justificadas em todas as circunstâncias e em todos os lugares e tempos". Assim, a ação dos bibliotecários e demais profissionais de informação devem estar pautadas em uma noção de ética que fundamente ações socialmente justas.

\section{Considerações finais}

É possível perceber, com amparo na valorização da informação nos diversos contextos, a relevância do desenvolvimento de competências em informação para a sociedade contemporânea. Na atual conjuntura, as funções educacionais dos tradicionais sistemas de recuperação de informação, na promoção do acesso e uso eficiente de ferramentas de informação, passam a ser analisadas com base em contextos sociais mais amplos e diversificados, reforçando a responsabilidade social dos profissionais da informação.

Entende-se que agir com responsabilidade social significa operar de modo ético e responsável ante os constantes desafios (e ambiguidades) inerentes às questões de informação. Assim, o desenvolvimento de competências em informação constitui ação socialmente justa dos modernos profissionais da informação, na medida em que o uso eficiente e crítico das informações se torna uma habilidade necessária para a inclusão social dos cidadãos contemporâneos.

As tradicionais ações de educação de usuários de bibliotecas, pensadas além da forma e acesso à informação, podem contribuir para a concretização da sociedade centrada em informação e conhecimento, fortemente dependente de um contínuo fluxo informacional no desenvolvimento das variadas atividades. Nelas, as competências em informação dos agentes sociais envolvidos determinam a sua consecução, com resultados mais amplos para as pessoas e para sociedade, na perspectiva de um aprendizado para toda a vida (lifelong learning).

\section{Referências}

ASSOCIATION COLLEGE OF RESEARCH LIBRARIES. Information literacy competency standards for higher education. Illinois, 2000.

BADKE, William. Foundations of information literacy: learning from Paul Zurkowski. Online, p. 48-50, jan./fev. 2010. 
BUARQUE, C. Papel social da universidade. Campinas: [s.n.], 1991.

CAREGNATO, Sônia Elisa. O desenvolvimento de habilidades informacionais: o papel das bibliotecas universitárias no contexto da informação digital em rede. Revista de Biblioteconomia \& Comunicação, Porto Alegre, v.8, p. 47-55, jan./dez. 2000.

CRONIN, Blaise. The sociological turn in information science. Journal of Information Science, v. 34, p. 465-475, 2008.

DUDZIAK, Elisabeth Adriana. Os faróis da sociedade da informação: uma análise crítica sobre a atuação da competência em informação no Brasil. Inf. \& Soc.: estudos, João Pessoa, v. 18, n. 2, p. 41-53, maio-ago. 2008.

DU MONT, Rosemary Ruhig. Ethics in librarianship: a management model. Library Trends, v. 40, n. 2, p. 201-15, 1991.

FLEMING, H. (Ed.). User education in academic libraries. London: The Library Association, (1990).

FREIRE, Gustavo Henrique de Araújo; FREIRE, Isa Maria. Introdução à Ciência da Informação. João Pessoa: UFPB, 2009.

FREIRE, Gustavo Henrique de Araújo. Ciência da Informação: temática, histórias e fundamentos. Perspectivas em Ciência da Informação, Belo Horizonte, v. 11, n. 1, p. 6-19, 2006.

FREIRE, Isa Maria. A responsabilidade social da Ciência da Informação na perspectiva da consciência possível. DataGramaZero, v. 5, n. 1, fev. 2004.

FROHMANN, B. Taking information policy beyond informacion science: applying the actor network theory. In: ANNUAL CONFERENCE OF THE CANADIAN ASSOCIATION FOR INFORMATION SCIENCE, 23., 1995, Edmonton, Alberta. Proceedings... Alberta, 1995.

FROHMANN, Bernard. O caráter social, material e público da informação. In: FUJITA, M. S.L., MARTELETO, R.M., LARA, M.L.G. de. A dimensão epistemológica da Ciência da Informação e suas interfaces técnicas, políticas e institucionais nos processos de produção, acesso e disseminação da informação. São Paulo: Cultura Acadêmica Ed. 2008. p. 17-34.

GONZÁLEZ DE GOMEZ, Maria Nélida. A informação como instância de integração de conhecimentos, meios e linguagens: questões epistemológicas, conseqüências políticas. In: GONZÁLEZ DE GOMEZ, Maria Nélida; ORRICO, Evelyn Goyannes Dill (Org.). Políticas de memória 
e informação: reflexos na organização do conhecimento. Natal: EDUFRN, 2006. p. 29-84.

GONZÁLEZ DE GOMEZ, Maria Nélida. Desafios contemporâneos da ciência da informação: as questões éticas da informação. In: ENCONTRO NACIONAL DE PESQUISA DA ASSOCIAÇÃO NACIONAL DE PESQUISA E PÓS-GRADUAÇÃO EM CIÊNCIA DA INFORMAÇÃO, 10., 2009, João Pessoa. Responsabilidade social da Ciência da Informação [trabalhos apresentados]. Organização de Gustavo Henrique de Araújo Freire. João Pessoa: UFPB, 2009. p. 106-126.

GONZÁLEZ DE GOMEZ, Maria Nélida. Escopo e abrangência da Ciência da Informação e a Pós-Graduação na área: anotações para uma reflexão. Transinformação, Campinas, v. 15, n. 1, p. 31-43, jan./abr. 2003.

HOYER, Jennifer. Information is social: information literacy in context. Reference Services Review, v. 39, n. 1, p. 10-23, 2011.

INSTITUTO NACIONAL DE ESTUDOS E PESQUISAS EDUCACIONAIS ANÍSIO TEIXEIRA (INEP). Sistema Nacional de Avaliação da Educação Superior (SINAES). 4. ed. Brasília, 2007.

KOLTAY, Tibor. The media and the literacies: media literacy, information literacy, digital literacy. Media, Culture \& Society, v. 33, n. 2, p. 211-221, 2011.

MINGUILI, Maria da Glória; CHAVES, Adriana Josefa; FORESTI, Miriam Celí Pimentel Porto. Universidade brasileira: visão histórica e papel social. In: OFICINA DE ESTUDOS PEDAGÓGICOS, 2007, Marília. [Anais...]. Marília: UNESP, 2007. Disponível em: <http://www.franca.unesp.br/oep/ Eixo\%201\%20-\%20Tema\%201.pdf>. Acesso em: 18 jul. 2010.

MOSTAFA, Solange Puntel. Ciência da informação: uma ciência, uma revista. Ciência da Informação, Brasília, v. 25, n. 3, 1996.

MOUNCE, Michael. Working Together: Academic Librarians and Faculty Collaborating to Improve Students' Information Literacy Skills: A Literature Review 2000-2009. The Reference Librarian, v. 51, n. 4, p. 300-320, 2010.

OWUSU-ANSAH, Edward K. Debating definitions of information literacy: enough is enough!. Library Review, v. 54, n. 6, p. 366-374, 2005.

PINHEIRO, L. V. R. Processo evolutivo e tendências contemporâneas da Ciência da Informação. Informação e Sociedade: estudos, v. 15, n.1, 2005. 
PINHEIRO, L. V. R. Ciência da informação e sociedade: uma relação delicada entre a fome de saber e de viver. In: ENCONTRO NACIONAL DE PESQUISA DA ASSOCIAÇÃO NACIONAL DE PESQUISA E PÓSGRADUAÇÃO EM CIÊNCIA DA INFORMAÇÃO, 10., 2009, João Pessoa. Responsabilidade social da Ciência da Informação [trabalhos apresentados]. Organização de Gustavo Henrique de Araújo Freire. João Pessoa: UFPB, 2009. p. 1-20.

PINTO, Maria; CORDÓN, José Antonio; DÍAZ, Raquel Gómez. Thirty years of information literacy (1977-2007): a terminological, conceptual and statistical analysis. Journal of Librarianship and Information Science, v. 42, n. 1, p. 3-19, mar. 2010.

SANTOS, Boaventura de Sousa. Um discurso sobre as ciências na transição para uma ciência pós-moderna. Estudos Avançados, São Paulo, v. 2, n. 2, p. 46-71, maio-ago. 1988.

SERAFIM, Lucas Almeida. Competências em informação na educação superior: um estudo com os professores do curso de Agronomia do Campus da UFC no Cariri. 147 f. 2011. Mestrado (Ciência da Informação) - Universidade Federal da Paraíba, João Pessoa, 2011.

SOCIETY OF COLLEGE, NATIONAL AND UNIVERSITY LIBRARIES. The SCONUL seven pillars of information literacy: core model for higher education. London, 2011. Disponível em: <http://www.sconul.ac.uk/groups/information_literacy/publications/corem odel.pdf >. Acesso em: 2 maio. 2011.

TÁLAMO, Maria de Fátima Gonçalves Moreira; SMIT, Johanna Wilhelmina. Ciência da informação: a transgressão metodológica. In: PINTO, Virgínia Bentes; CAVALCANTE, Lídia Eugênia; SILVA NETO, Casemiro (Org.). Ciência da informação: abordagens transdiciplinares. Fortaleza: UFC, 2007. p. 23-104.

VALLAEYS, François. Que significa responsabilidade social universitária? Revista da Associação Brasileira de Mantenedoras de Ensino Superior, Brasília, ano 24, n. 36, ju. 2006.

VAN DIJCK, José. Search engines and the production of academic knowledge. International Journal of Cultural Studies, v. 13, p. 574-592, 2010.

VIRKUS, Sirje. Information literacy in Europe: a literature review. Information Research, v. 8, n. 4, jul. 2003. 
WALSH, John. Librarians and controlling disinformation: is multi-literacy instruction the answer?. Library Review, v. 59, n. 7, p. 498-511, 2010.

WERSIG, Gernot. Information Science: the study of postmodern knowledge usage. Information Processing Management, v.29, n.2, p.229239, 1993.

WERSIG, Gernot; NEVELLING, $U$. The phenomena of interest to information science. The information Scientist, v. 9, n. 4, 1975.

ZHANG, Xue; MAJID, Shaheen; FOO, Schubert. Environmental scanning: An application of information literacy skills at the workplace. Journal of Information Science, v. 36, n. 6, p. 719-732, 2010.

ZURKOWSKI, Paul G. The Information Service Environment Relationships and Priorities: related paper $\mathrm{n}^{\circ}$ 5. Washington: National Commission on Libraries and Information Science, 1974. 